\title{
Análise energética e exergética de um motor de ignição por compressão operando
}

\section{com diesel e biodiesel}

\author{
Energetic and exergetic analysis of compression ignition with diesel and biodiesel \\ Análisis energético y exergético de um motor de encendido por compresíon que funciona com diesel \\ y biodiesel
}

Recebido: 17/11/2021 | Revisado: 21/11/2021 | Aceito: 27/11/2021 | Publicado: 09/12/2021

\author{
Débora Coraça Possa \\ ORCID: https://orcid.org/0000-0003-2172-0130 \\ Universidade do Oeste do Paraná, Brasil \\ E-mail: deboracpossa@gmail.com \\ Samuel Nelson Melegari de Souza \\ ORCID: https://orcid.org/0000-0002-3581-902X \\ Universidade do Oeste do Paraná, Brasil \\ E-mail: Samuel.souza@unioeste.br \\ Eliseu Avelino Zanella Junior \\ ORCID: https://orcid.org/0000-0002-5674-731X \\ Universidade Paranaense, Brasil \\ E-mail: jzanella@terra.com.br \\ Edson Antônio da Silva \\ ORCID: https://orcid.org/0000-0003-3978-5346 \\ Universidade do Oeste do Paraná, Brasil \\ E-mail: edsondeq@gmail.com \\ Desirè Coraça Possa \\ ORCID: https://orcid.org/0000-0002-4115-348X \\ Universidade do Oeste do Paraná, Brasil \\ E-mail: desicpossa@gmail.com \\ Carlos Eduardo Camargo Nogueira \\ ORCID: https://orcid.org/0000-0003-3886-9118 \\ Universidade do Oeste do Paraná, Brasil \\ E-mail: cecn1@yahoo.com.br
}

\begin{abstract}
Resumo
Os impactos econômicos e ambientais ao uso de combustíveis fósseis tem incentivado a busca de fontes renováveis de energia. Em regiões isoladas é comum o emprego de geradores a diesel para a geração de energia elétrica. Assim o biodiesel se mostra uma grande alternativa para geradores elétricos. Neste estudo foram realizados a análise energética e exergética em um conjunto motor gerador ciclo diesel submetidos a 5 cargas alternadas operando com 5 misturas de combustíveis em diferentes porcentagens entre o diesel e o biodiesel de óleo de canola. Foram realizados 25 ensaios com o conjunto motor-gerador para estabelecer o consumo específico do combustível, temperatura dos gases de exaustão, energia do combustível, eficiência térmica, energia dos gases de exaustão, perdas por transferência de calor, exergia do combustível, eficiência exergética, exergia dos gases de exaustão, exergia destruída e a exergia das perdas por transferência de calor. Verificou-se que com o aumento da carga o consumo específico de combustível reduziu e o diesel puro exibiu o menor consumo. A maior eficiência térmica exibida foi para a mistura de B100 nas cargas de 2000 W e $2500 \mathrm{~W}$. O biodiesel puro com carga de $2000 \mathrm{~W}$ e $2500 \mathrm{~W}$ apresentou a eficiência exergética mais alta e as misturas com maior porcentagem de biodiesel exibiram menor destruição de exergia.
\end{abstract}

Palavras-chave: Termodinâmica; Ciclo diesel; Exergia; Energia.

\begin{abstract}
The economic and environmental impacts related with fossil fuels dependency have encouraged the source of renewable energy sources. In remotes areas is common to use the diesel-generators for electric power generation. So, the biodiesel proves to be a great alternative for the electric generators. In this study was realized the energy and exergetic analysis of an engine-generator group diesel cycle subject to 5 alternating charges operating with 5 mixtures of fuel at different percentages between diesel and canola biodiesel. It was realized 25 essays in the engine-generator group to establish the specific fuel consumption, exhaust gas temperature, fuel energy, thermal efficiency, exhaust gas energy, heat transfer losses, fuel exergies, exergetic efficiency, exhaust gas exergy, destroyed exergy and the exergy of the heat transfer losses. It was found by increases in charge the specific fuel consumption lowers and the pure diesel showed the lowest consumption. At $2000 \mathrm{~W}$ and $2500 \mathrm{~W}$ the pure biodiesel has the best thermal efficiency. The pure biodiesel at $2000 \mathrm{~W}$
\end{abstract}


and $2500 \mathrm{~W}$ has the best exergetic efficiency and the blends with the biggest biodiesel percent showed the lowest exergy destruction.

Keywords: Thermodynamics; Diesel cycle; Exergy; Energy.

\begin{abstract}
Resumen
Los impactos económicos y ambientales relacionados con el uso de combustibles fósiles han contribuido la busca por fuentes renovables de energía. En regiones más remotas es común el empleo de grupos electrógenos diesel para la generación de energía eléctrica. Por así el biodiésel se muestra una grande alternativa para grupos electrógenos. En este estudio fueron realizados el análisis energético y exergético en un conjunto motor generador ciclo diesel sometidos a 5 cargas alternadas operando con 5 mezclas de combustibles en diferentes porcentajes entre diésel y el biodiésel de aceite de canola. Fueron efectuados 25 ensayos con el conjunto motor generador para determinar el consumo específico de combustible, eficiencia térmica, energía de los gases del sistema de escape, pérdidas por transferencia de calor, exergía del combustible, eficiencia exergética, exergía de los gases del sistema de escape, exergía destruida y la exergía de las pérdidas por transferencia de calor. Se verificó que con el aumento de la carga el consumo específico del combustible disminuyó y el diésel puro presenta el menor consumo. La mayor eficiencia térmica demostrada fue la mezcla de B100 en las cargas de $2000 \mathrm{~W}$ y $2500 \mathrm{~W}$. El biodiésel puro con carga de $2000 \mathrm{~W}$ y $2500 \mathrm{~W}$ presentó la eficiencia exergética más alta y las mezclas con mayor porcentaje de biodiésel demostraron menor destrucción de exergía.
\end{abstract}

Palabras clave: Termodinámica; Ciclo diesel; Exergia; Energia.

\title{
1. Introdução
}

Os combustíveis fósseis são amplamente empregados em automóveis, no setor agrícola, para o desenvolvimento industrial, entre outras utilidades. O seu elevado consumo auxilia com o efeito estufa e impulsiona a emissão de poluentes para a atmosfera. Com o aumento da demanda de energia atrelado ao inevitável esgotamento das fontes de combustíveis fósseis, surge a necessidade de realizar pesquisas que encontrem fontes alternativas de energias renováveis e mais ecológicas (Chuah, et al., 2016, 2017).

Nesse contexto, o biodiesel se transforma em uma alternativa de combustível, sendo uma fonte de energia sustentável e renovável, auxiliando na redução dos efeitos causados pela poluição ambiental (Patel \& Sankhavara, 2017). Quando comparado com os combustíveis fósseis, os biocombustíveis exibem uma melhor biodegradabilidade e toxicidade inferior (Knothe \& Razon, 2017).

O biodiesel é um grande substituto para o petróleo no setor de transporte, já que pode ser combinado com combustíveis fósseis para ser utilizado sem nenhuma transformação mecânica necessária em motores movidos a diesel. (Ouanji, et al., 2016). Podem ser utilizados para fabricação do biocombustível vários tipos de óleos, já utilizados ou novos, de origem animal ou vegetal (Brennan \& Owende, 2010; Gashaw \& Teshita, 2014; Ouanji, et al., 2016).

A produção de biodiesel vem crescendo com o passar dos anos sendo que em dez anos teve um crescimento de mais de $360 \%$ no Brasil (ANP, 2020). Como o biodiesel é um combustível biodegradável adquirido por fontes renováveis, políticas voltadas para o incentivo de sua utilização vêm ganhando espaço, como a obrigatoriedade da incorporação do biodiesel ao óleo diesel que entrou em vigor em 2008. De acordo com Meira, et al. (2016) a combinação do biodiesel ao óleo diesel contribui na redução de $\mathrm{CO}, \mathrm{CO}_{2}$ e enxofre.

Tratando-se de motores, a utilização do biodiesel auxilia no seu desempenho devido aos hidrocarbonetos de cadeia mais longa, presentes em sua formação, quando em comparação com a gasolina (Bergthorson \& Thomson, 2015).

$\mathrm{Na}$ agricultura o motor diesel é amplamente utilizado devido à robustez, confiabilidade, maior produção de torque $\mathrm{e}$ vida útil, oferecendo ainda menor consumo e rendimento superior comparando-se aos motores ciclo Otto. Ainda, o motor diesel é a principal fonte de energia no setor de transporte público, de cargas, indústria naval, mineração, e são muito utilizadas também em pequenas e médias unidades de geração elétrica, sendo responsável por cerca de 10-15\% do total da capacidade instalada no mundo (Kanoglu, et al., 2005).

Atualmente existem vários estudos sobre análise exergética aplicada a sistemas térmicos, principalmente focados em motores de combustão interna. No que se refere à motores ciclo diesel, alguns autores realizaram pesquisas sobre a análise 
energética e exergética do mesmo, empregando diferentes percentuais de biodiesel ao óleo diesel, e obtiveram resultados satisfatórios quanto a utilização de biodiesel (López, et al., 2014; Buyukkava, et al., 2014; Karthikeyan \& Jayaprabakar, 2017; Oliveira, 2018; Yasmin, et al., 2018; Jannatkhah, et al., 2019; Karthickeyan, 2019).

Nesse contexto, o objetivo deste trabalho é realizar a análise energética e exergética em conjunto gerador operando com um motor de ignição por compressão com diferentes misturas entre óleo diesel e o biodiesel de óleo de canola, analisando o consumo específico do combustível, a energia proveniente do combustível, a energia proveniente dos gases de exaustão, a energia proveniente das perdas por transferência de calor, a eficiência térmica do sistema, a exergia do combustível, a exergia dos gases de exaustão, a exergia das perdas por transferência de calor, a exergia destruída e a eficiência exergética para as diferentes misturas de combustíveis e cargas.

\section{Metodologia}

O estudo foi realizado no Laboratório de Gaseificação de Biomassa e Microgeração de Eletricidade, localizado na Universidade Estadual do Oeste do Paraná - UNIOESTE, Campus de Cascavel - PR. Os combustíveis avaliados neste trabalho foram cinco misturas entre diesel e biodiesel de óleo de canola sendo elas B0 (diesel puro), B10 (10\% de biodiesel e $90 \%$ de diesel), B20 (20\% de biodiesel e 80\% de diesel), B30 (30\% de biodiesel e 70\% de diesel) e B100 (biodiesel puro).

O diesel (S10) foi adquirido em comércio local, este combustível apresentava densidade de $834,2 \mathrm{~kg} / \mathrm{m}^{3}$ a $20^{\circ} \mathrm{C}$ e viscosidade de 2,0-4,5 cSt a $40^{\circ} \mathrm{C}$. O biodiesel foi fornecido por alunos do programa de pós-graduação da UNIOESTE, o mesmo foi produzido a partir do óleo de canola pelo método de transesterificação e passou pelo processo de lavagem e secagem. Realizou-se a caracterização do combustível através da determinação de sua densidade pela norma NBR 14065 (ABNT, 2013) e sua viscosidade pela norma NBR 10441 (ABNT,2014).

O conjunto motor gerador empregado neste estudo trata-se de um sistema eletromecânico ciclo diesel, monocilíndrico, refrigerado a ar, quatro tempos, da marca Branco, modelo BD-4000, o conjunto possui potência máxima de 3,3 kVA com partida manual.

No ensaio, submeteu-se o grupo gerador a cinco cargas resistivas diferentes com os valores de $500 \mathrm{~W}, 1000 \mathrm{~W}, 1500$ W, $2000 \mathrm{~W}$ e $2500 \mathrm{~W}$, não foi avaliado o motor a $3000 \mathrm{~W}$ pela alta taxa de emissão de poluentes que podem danificar o analisador de gases. Inicialmente o grupo gerador operou por 20 minutos com óleo diesel para garantir que o grupo atingisse a temperatura de trabalho.

Para cada carga ensaiada coletou-se os dados num intervalo de 3 minutos e aguardou-se o tempo de 60 segundos entre um ensaio e outro para assegurar a estabilização do grupo gerador. Empregou-se um cronômetro para medir os tempos de coleta de dados. Para simular tais cargas, utilizou-se um banco de cargas resistivas. Realizou-se quatro ensaios para cada blenda de combustível com a sua respectiva carga definida, totalizando 25 ensaios.

Para medir o consumo volumétrico de combustível durante o intervalo de tempo do ensaio foi utilizado uma proveta plástica graduada em $\mathrm{mL}$. As vazões mássicas dos combustíveis foram encontradas a partir da multiplicação do volume consumido pela densidade do combustível e dividindo este produto pelo tempo de duração do ensaio.

$$
\dot{m}_{c o m b}=\frac{v_{c o m b} . D}{t}
$$

Para alguns cálculos empregou-se a vazão molar dos combustíveis, sendo obtido a partir da Equação 2.

$$
\dot{n}_{c o m b}=\dot{m}_{c o m b} \cdot M W_{c o m b}
$$


Não foi possível realizar a medição da vazão mássica, velocidade e temperatura do ar de admissão no motor, para fins de cálculos foi considerado o seu valor correspondente para uma mistura estequiométrica. Para verificar a temperatura dos gases de exaustão, utilizou-se um analisador de gases da marca Bacharach modelo PCA®3.

Estudou-se o comportamento termodinâmico do conjunto motor-gerador de acordo com a primeira e segunda lei da termodinâmica, considerando que o estado de referência é de $25^{\circ} \mathrm{C}(298,15 \mathrm{~K})$ e $1 \mathrm{~atm}(101325 \mathrm{~Pa})$. Os cálculos foram realizados com base no volume de controle ilustrado na Figura 1, considerando um sistema aberto em regime permanente, desprezando-se a energia cinética e potencial, que o ar e os gases de exaustão como gases ideais e que não foi fornecido nenhum trabalho e nenhuma energia em forma de transferência de calor para o volume de controle.

Figura 1 - Volume de controle definido para o grupo motor-gerador.

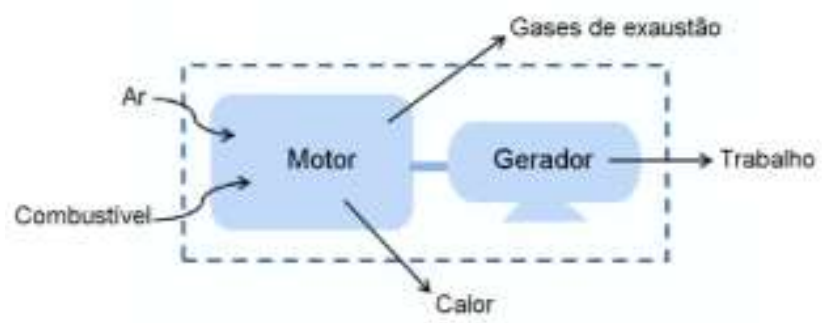

Fonte: Autores.

Jannatkhah, et al. (2019) exibem algumas propriedades físico-químicas do diesel e biodiesel abordados neste estudo, como mostra a Tabela 1.

Tabela 1 - Propriedades físico-químicas do diesel e do biodiesel de óleo de canola.

\begin{tabular}{ccc}
\hline Propriedades & Diesel & Biodiesel \\
\hline Fórmula & $\mathrm{C}_{14,09} \mathrm{H}_{24,78}$ & $\mathrm{C}_{18,29} \mathrm{H}_{34,08} \mathrm{O}_{2}$ \\
Massa molecular média $(\mathrm{kg} / \mathrm{kmol})$ & 194,2 & 285,59 \\
Poder calorífico inferior $(\mathrm{kJ} / \mathrm{kg})$ & 42640 & 37381,96 \\
Entalpia de formação $(\mathrm{kJ} / \mathrm{kmol})$ & -260159 & $-514095,29$ \\
Exergia química $(\mathrm{kJ} / \mathrm{kmol})$ & 8823042,58 & 927080,424 \\
\hline
\end{tabular}

Fonte: Jannatkhanh, Najafi e Ghaebi (2019).

Considerou-se que a composição do ar é igual a $21 \%$ de oxigênio $\left(\mathrm{O}_{2}\right)$ e $79 \%$ de nitrogênio $\left(\mathrm{N}_{2}\right)$. A reação de combustão completa para uma mistura estequiométrica é demonstrada na Equação 3, sendo $a C_{x 1} H_{y 1}$ é a representação de um kmol de diesel, $b C_{x 2} H_{y 2} O_{z 2}$ é a representação de um kmol de biodiesel.

$$
a C_{x 1} H_{y 1}+b C_{x 2} H_{y 2} O_{z 2}+c\left(O_{2}+3,76 N_{2}\right) \rightarrow d C O_{2}+e N_{2}+f H_{2} \mathrm{O}
$$

Desde que a fórmula química do combustível é conhecida e aplicando o balanço de massa de cada componente na reação, os coeficientes desconhecidos podem ser calculados. A Tabela 2 apresenta os coeficientes estequiométricos para cada mistura de combustível ensaiada. 
Tabela 2 - Coeficientes da reação de combustão com mistura e estequiométrica com combustão completa.

\begin{tabular}{cccccc} 
& B0 & B10 & B20 & B30 & B100 \\
\hline $\boldsymbol{a}$ & 1 & 0,9 & 0,8 & 0,7 & 0 \\
$\boldsymbol{b}$ & 0 & 0,1 & 0,2 & 0,3 & 1 \\
$\boldsymbol{c}$ & 20,285 & 20,838 & 21,39 & 21,943 & 25,81 \\
$\boldsymbol{d}$ & 14,09 & 14,51 & 14,93 & 15,35 & 18,29 \\
$\boldsymbol{e}$ & 76,272 & 78,349 & 80,426 & 82,504 & 97,046 \\
$\boldsymbol{f}$ & 12,39 & 12,855 & 13,32 & 13,785 & 17,04 \\
\hline
\end{tabular}

Fonte: Autores..

\subsection{Balanço energético}

A Equação 4 representa o balanço da primeira lei da termodinâmica em base de 1 kmol de combustível para o volume de controle estabelecido.

$$
\frac{\dot{Q}_{a}}{\dot{n}_{c o m b}}-\frac{\dot{W}_{s}}{\dot{n}_{c o m b}}=\bar{h}_{g e}-\bar{h}_{c o m b}-\bar{h}_{a r}
$$

Sendo $\dot{Q}_{a}$ a taxa de troca de calor $(\mathrm{kW}), \dot{W}_{s}$ a potência efetiva do motor $(\mathrm{kW}), \dot{n}_{c o m b}$ a vazão molar do combustível (kmol/s), $\bar{h}_{g e}$ a entalpia dos gases de exaustão (kJ/kmol combustível), $\bar{h}_{c o m b}$ entalpia do combustível (kJ/kmol combustível) e $\bar{h}_{a r}$ a entalpia do ar (kJ/kmol combustível). Considerou-se que as condições do dia dos ensaios foram realizadas em condições semelhantes ao do estado de referência estabelecido, desta forma, pode-se desprezar a energia presente no ar admitido.

A entalpia absoluta do combustível é demonstrada pela Equação 5.

$$
\bar{h}_{\text {comb }}(T)=\bar{h}_{f, c o m b}^{o}\left(T_{r e f}\right)+\Delta \bar{h}_{s, c o m b}(T)
$$

Onde $\Delta \bar{h}_{s, c o m b}(T)$ é variação de entalpia sensível do combustível e $\bar{h}_{f, c o m b}^{o}$ a entalpia de formação do combustível expressa $(\mathrm{kJ} / \mathrm{kmol})$ na temperatura de referência $T_{\text {ref }}$. Considerou-se que o combustível é admitido no volume de controle em condição semelhante ao do estado de referência, assim a variação de entalpia sensível do combustível é nula. As propriedades termodinâmicas necessárias para os cálculos foram obtidas a partir das tabelas termodinâmicas dispostas por Turns (2013).

Para o cálculo da entalpia de formação do combustível considerou-se a definição do poder calorífico e da reação estequiométrica de combustão, conforme Equação 6.

$$
\overline{P C I}=d\left(\bar{h}_{f}^{0}\right)_{C O_{2}}+f\left(\bar{h}_{f}^{0}\right)_{H_{2} O(g)}+e\left(\bar{h}_{f}^{0}\right)_{N_{2}}-\left(\bar{h}_{f}^{0}\right)_{c o m b}-c\left(\bar{h}_{f}^{0}\right)_{O_{2}}-3,76 c\left(\bar{h}_{f}^{0}\right)_{N_{2}}
$$

Onde $\bar{h}_{f, \mathrm{CO}_{2}}^{o}, \bar{h}_{f, \mathrm{H}_{2} \mathrm{O}}^{o}, \bar{h}_{f, \mathrm{~N}_{2}}^{o}, \bar{h}_{f, \mathrm{O}_{2}}^{o}$, são as entalpias de formação no estado de referência das espécies $\mathrm{CO}_{2}, \mathrm{H}_{2} \mathrm{O}, \mathrm{N}_{2} \mathrm{e}$ $\mathrm{O}_{2}$, respectivamente, dispostos na Tabela 3. Deste modo, a partir da Equação 8 calculou-se a entalpia de formação do combustível no estado de referência. 
Tabela 3 - Entalpia de formação a 298,15 K para alguns gases.

\begin{tabular}{ccc}
\hline Fórmula & Gás & $\begin{array}{c}\text { Entalpia de formação } \\
\bar{h}_{f, i}^{o}(\mathrm{~kJ} / \mathrm{kmol})\end{array}$ \\
\hline $\mathrm{CO}_{2}$ & Dióxido de carbono & -393546 \\
$\mathrm{H}_{2} \mathrm{O}$ & Água & -241845 \\
$\mathrm{~N}_{2}$ & Nitrogênio & 0 \\
$\mathrm{O}_{2}$ & Oxigênio & 0 \\
\hline
\end{tabular}

Fonte: adaptado de Turns (2013).

O cálculo para as entalpias $\bar{h}_{g e}$ e $\bar{h}_{a r}$ foram realizados a partir da Equação 7, expressa em kJ de combustível. Sendo $n_{i}$ o número de kmol da espécie $i$ por kmol de combustível e $\bar{h}_{i}$ a entalpia absoluta da espécie $i$ (kJ/kmol de espécie i).

$$
\bar{h}_{m}=\sum_{i=1}^{N} n_{i} \bar{h}_{i}
$$

Calculou-se a energia perdida nos gases de exaustão $(\mathrm{kW})$ a partir da Equação 8.

$$
\dot{Q}_{g e}=\dot{n}_{c o m b} \overline{P C I}-\dot{W}_{s}-\dot{Q}_{a}
$$

A eficiência energética foi calculada de acordo com a Equação 9.

$$
\eta=\frac{\dot{W}_{S}}{\dot{m}_{c o m b} P C I}
$$

O consumo específico de combustível é dado pela Equação 10.

$$
C S E=\frac{\dot{m}_{c o m b}}{\dot{W}_{S}}
$$

\subsection{Balanço exergético}

O balanço da segunda lei da termodinâmica ou o balanço de exergia para o volume de controle estabelecido em base a 1 kmol de combustível é expressa conforme a Equação 11.

$$
\sum\left(1-\frac{T_{0}}{T_{i}}\right) \dot{Q}_{a}-\dot{W}_{s}+\dot{n}_{c o m b} \bar{e}_{c o m b}-\dot{n}_{c o m b} \bar{e}_{g e}-\dot{E}_{D}=0
$$

Onde $\bar{e}_{\text {comb }}$ e $\bar{e}_{g e}$ são as exergias de escoamento do combustível e dos gases de exaustão respectivamente dado em $\mathrm{kJ} / \mathrm{kmol}$ de combustível, $\dot{E}_{D}$ é a taxa de destruição de exergia em $\mathrm{kW}$ e $T_{i}$ a temperatura na saída da fronteira do volume de controle.

Como foi considerado que os ensaios foram realizados em condições semelhantes ao do estado de referência a exergia química e física do ar e a exergia física do combustível no balanço de energia podem ser desconsiderados, como demonstrado por Canakci e Hosoz (2006). A exergia química do combustível é expressa pela Equação 12 (Kotas, 1985). 


$$
\bar{e}_{c o m b}^{c h}=\operatorname{PCI}\left(1,0374+0,01594 \frac{h}{c}+0,0567 \frac{o}{c}\right)
$$

A exergia específica dos gases de exaustão é a soma da exergia física específica mais a exergia química específica de uma mistura gasosa. A Equação 13 exibe a exergia física específica para os gases de exaustão expressa em kJ/kmol (Moran \& Shapiro, 2018).

$$
\bar{e}_{g e}^{t h}=\sum_{i=1}^{N} n_{i}\left\{\bar{h}_{i(T)}-\bar{h}_{o, i}-T_{r e f}\left[\bar{s}_{\left(T, p_{r e f}\right), i}-\bar{s}_{o, i}-\bar{R} \ln y_{i}\right]\right\}
$$

Onde $\bar{h}_{i(T)}$ e $\bar{h}_{o, i}$ são às entalpias da espécie $i$ nas temperaturas $T$ e $T_{r e f}$ dada em kJ/kmol, $\bar{s}_{\left(T, p_{r e f}\right), i}$ e $\bar{s}_{o, i}$ correspondem às entropias da espécie $i$ nas condições de $\left(T, p_{r e f}\right)$ e $\left(T_{r e f}, p_{r e f}\right)$ em kJ/kmol.K, $\bar{R}$ representa a constante universal dos gases $(8,314 \mathrm{~kJ} / \mathrm{kmol} . \mathrm{K})$ e $y_{i}$ e a fração molar da espécie $i$ na mistura gasosa.

Calculou-se a exergia química específica dos gases de exaustão dada em kJ/kmol de combustível a partir da Equação 14.

$$
\bar{e}_{g e}^{c h}=\bar{R} T_{r e f} \sum_{i=1}^{N} n_{i} \ln \left(\frac{y_{i}}{y_{i}^{e}}\right)
$$

Onde $y_{i}$ é a fração molar da espécie $i$ na condição real de $(T, p)$ e $y_{i}^{e}$ a fração molar de referência de cada espécie $i$ segundo Szargut, Morris e Steward (1988), conforme mostrado na Tabela 3.

Tabela 4 - Frações molares de referência.

\begin{tabular}{cc}
\hline Espécie química & Fração molar $\left(y_{i}^{e}\right)$ \\
\hline $\mathrm{N}_{2}$ & 0,76307 \\
$\mathrm{O}_{2}$ & 0,205317 \\
$\mathrm{H}_{2} \mathrm{O}$ & 0,022153 \\
$\mathrm{CO}_{2}$ & 0,000337 \\
$\mathrm{Ar}$ & 0,009123 \\
\hline
\end{tabular}

Fonte: Szargut, Morris e Steward (1988).

A eficiência exergética do sistema é expressa através da Equação 15.

$$
\varepsilon=\frac{\dot{w}_{s}}{\dot{n}_{c o m b} \bar{e}_{c o m b}}
$$

\section{Resultados e Discussão}

\subsection{Análise físico-química do biodiesel}

As qualidades do biodiesel de canola foram avaliadas através da densidade e da viscosidade. A densidade do biodiesel está dentro do estabelecido pela norma NBR 14065, sendo $872,3105 \mathrm{~kg} / \mathrm{m}^{3}$. A viscosidade cinemática do biodiesel se encontra dentro do especificado pela norma NBR 10441, correspondendo a $4,032 \mathrm{~mm}^{2} / \mathrm{s}$ 


\subsection{Análise energética}

Os valores encontrados para entalpia de formação é de $-260834,69 \mathrm{~kJ} / \mathrm{kmol}$ para o diesel e $-643081 \mathrm{~kJ} / \mathrm{kmol}$ para o biodiesel. Esses resultados demonstraram ser próximos aos calculados por Jannatkhanh, Najafi e Ghaebi (2019), que dentre os combustíveis ensaiados também avaliaram misturas entre combustível óleo diesel e o biodiesel de óleo de canola.

\subsubsection{Consumo específico de combustível}

A Figura 2 exibe o consumo específico de combustível (CSE) em g/kW. Observa-se que este dado tende a diminuir conforme se aumenta a carga, o mesmo ocorreu nos trabalhos de Yamin, et al. (2018) e Karthickeyan (2019).

O maior consumo específico de combustível foi para a mistura de B100 com carga de $500 \mathrm{~W}$. Observa-se que esta mistura apresentou os maiores valores de consumo, com exceção para a carga de $1000 \mathrm{~W}$.

O ponto que demonstrou menor consumo específico de combustível foi para a mistura de B0 com carga de 2000 e 2500 W. No trabalho de Oliveira (2018) o maior ponto de consumo também foi para a menor potência com a maior porcentagem de biodiesel na mistura, e o menor consumo específico para a maior potência com diesel puro.

Figura 2 - (a) Consumo específico de combustível para os combustíveis testados e a (b) energia do combustível para os combustíveis testados.

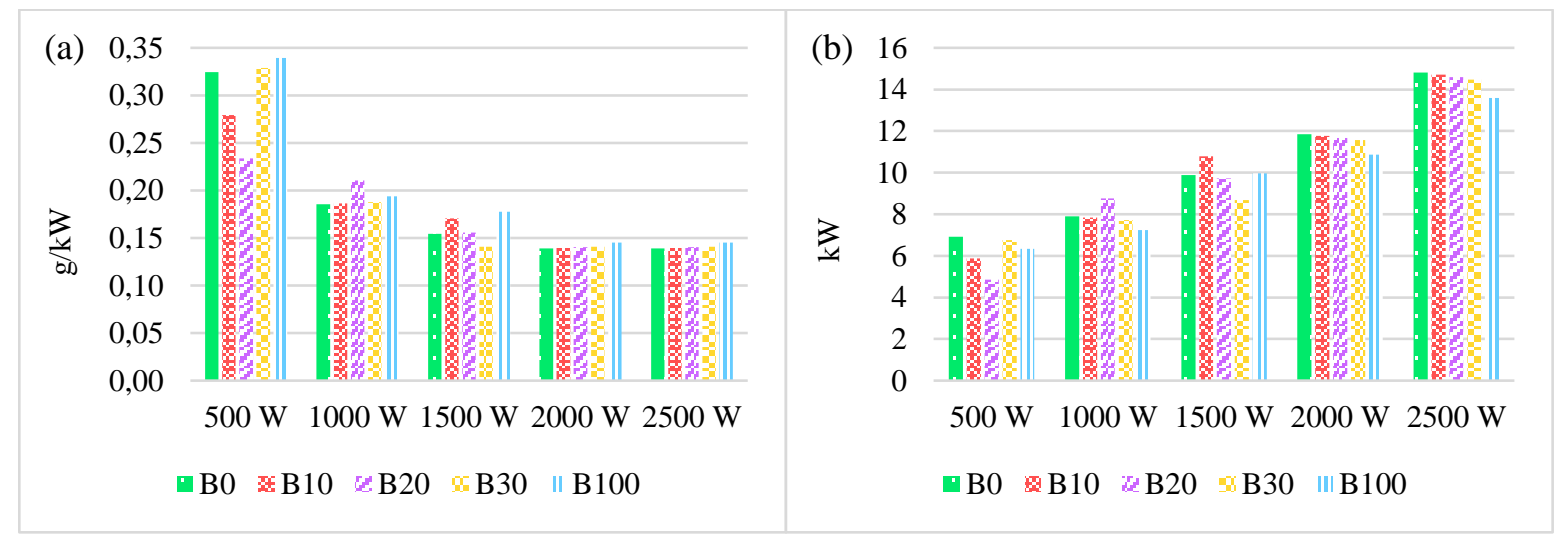

Fonte: Autores.

\subsubsection{Energia do combustível}

A energia do combustível $\left(\dot{n}_{\text {comb }} \overline{P C I}\right)$ fornecida ao motor de acordo com diferentes pontos de carga estabelecidos é exibido na Figura 2. Nota-se que à medida que se aumentava a carga a energia do combustível também aumenta.

Nos trabalhos de Oliveira (2018), Karthickeyan (2019) e Jannatkhanh, et al. (2019) a energia do combustível para o diesel puro foi maior que para os testes com mistura de biodiesel e a menor foi dada para a mistura de biodiesel puro. Neste estudo chegou-se a resultados semelhantes para as cargas de $1000 \mathrm{~W}, 2000 \mathrm{~W}$ e $2500 \mathrm{~W}$, os pontos onde as misturas de B0 não alcançaram o maior valor de energia de combustível e o B100 não alcançou o menor valor de energia do combustível é devido a vazão de combustível no momento do ensaio.

Para as cargas de $1000 \mathrm{~W}, 2000 \mathrm{~W}$ e $2500 \mathrm{~W}$ a menor energia de combustível foi para a mistura de B100, como apresentado pelos estudos de Oliveira (2018), Karthickeyan (2019) e Jannatkhanh, et al. (2019). Para a carga de $500 \mathrm{~W}$ a menor energia do combustível foi para a mistura de B20 e para a carga de $1500 \mathrm{~W}$ para a mistura de B30, chegou-se a este resultado devido a vazão de combustível neste ponto ser menor que para as outras misturas na mesma carga ensaiada. 


\subsubsection{Eficiência térmica}

Na Figura 3 são mostradas as eficiências térmicas dos combustíveis testados. O aumento da eficiência térmica ocorre junto com o aumento da carga aplicada. À medida que se aumentava a carga aumentava-se a eficiência térmica do sistema.

Em um parâmetro geral observou-se que as misturas com maior porcentagem de biodiesel exibiram maiores valores de eficiência térmica, para as cargas de $1000 \mathrm{~W}, 2000 \mathrm{~W}$ e $2500 \mathrm{~W}$ a mistura de B100 exibiu o maior rendimento térmico correspondendo $13,8 \%$ para $1000 \mathrm{~W}$ e de $18,40 \%$ para as cargas de $2000 \mathrm{~W}$ e $2500 \mathrm{~W}$, o mesmo foi visto no trabalho de Karthikeyan e Jayaprabakar (2017), Yamin, et al. (2018) e Jannatkhanh, et al. (2019), com exceção para a carga de $1000 \mathrm{~W}$ com mistura de B20 e para a carga de $1500 \mathrm{~W}$ para a mistura de B10 que por exibirem energia do combustível maior a sua eficiência térmica tende a diminuir.

Observou-se que para as cargas de $2000 \mathrm{~W}$ e $2500 \mathrm{~W}$ os valores de eficiência térmica foram exatamente os mesmos para cada mistura, isso ocorreu devido a vazão de combustível para estas faixas do ensaio serem constantes e haver um aumento proporcional desta vazão na carga de $2000 \mathrm{~W}$ para a de $2500 \mathrm{~W}$.

Figura 3 - (a) Eficiência térmica para os combustíveis testados e (b) energia dos gases de exaustão para os combustíveis testados.
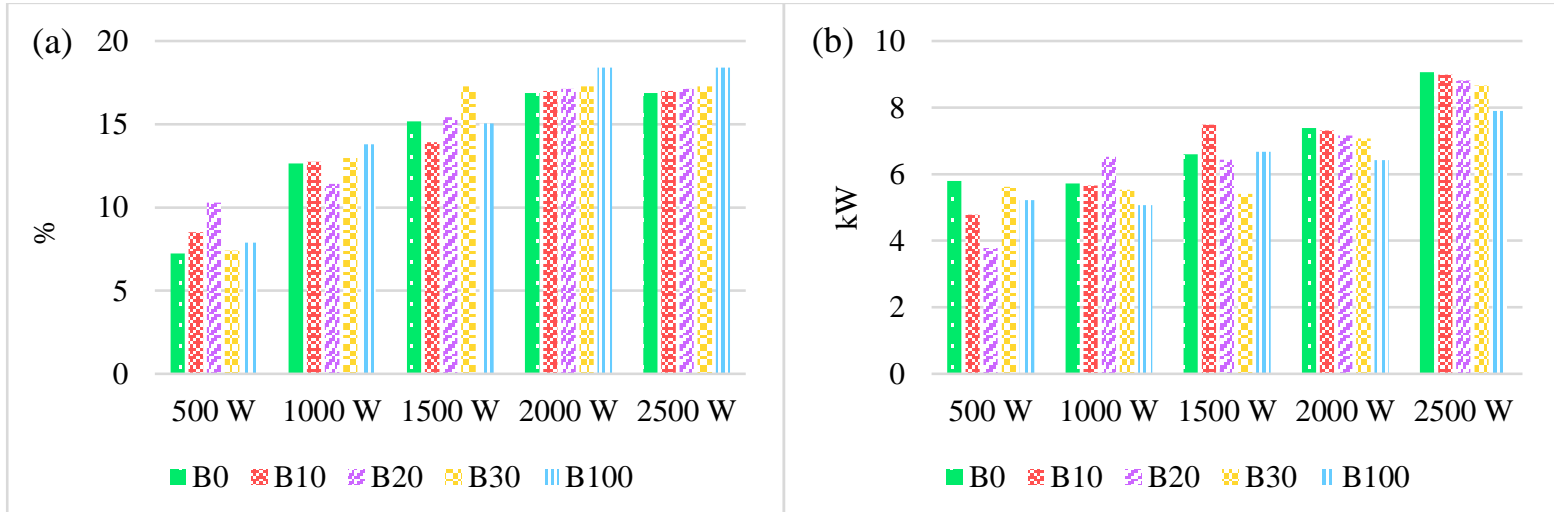

Fonte: Autores.

\subsubsection{Energia dos gases de exaustão}

A energia proveniente dos gases de exaustão é ilustrada na Figura 3. Para cada mistura de combustível observou-se que os resultados foram diretamente proporcionais, ou seja, ao aumentar a carga verificou-se que a energia dos gases de exaustão também aumentou. Segundo Aghbashlo, et al. (2015) a energia de escape aumentou com a carga, uma vez que o consumo de combustível e a temperatura dos gases de escape aumentaram.

Nos trabalhos de Buyukkaya, et al. (2014), Karthikeyan e Jayaprabakar (2017), Oliveira (2018) e Jannatkhanh, et al. (2019), é visto que a adição de biodiesel na mistura contribuiu para uma redução da energia dos gases de exaustão. Neste trabalho foi possível observar este comportamento para as cargas de $2000 \mathrm{~W}$ e $2500 \mathrm{~W}$, para a carga de $500 \mathrm{~W}$ as misturas de B10 e B20 fogem deste comportamento devido a sua vazão de combustível serem menores que as outras para esta mesma faixa de potência. Assim como para a carga de $1000 \mathrm{~W}$ para a mistura de B20 por apresentar uma vazão maior que as demais para esta mesma faixa de potência e para a carga de $1500 \mathrm{~W}$ para as misturas de B10, por ter uma vazão superior, e B30, por ter uma vazão inferior que as demais vazões para esta mesma faixa de potência. 


\subsubsection{Perdas por transferência de calor}

As perdas em razão da transferência de calor por parte do motor que ultrapassaram as fronteiras do volume de controle são exibidas na Figura 4. Observou-se que as perdas aumentam conforme se aumentava a carga.

Figura 4 - (a) Perdas por transferência de calor para os combustíveis testados e (b) exergia do combustível para os combustíveis testados.
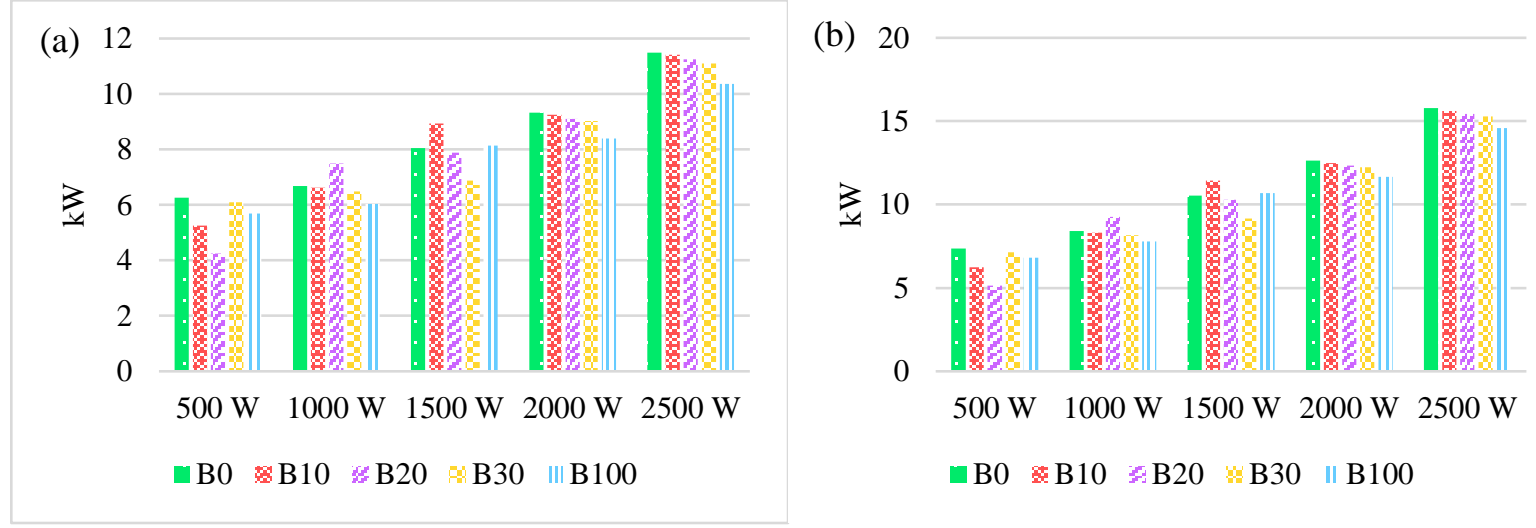

Fonte: Autores.

No estudo de Jannatkhanh, et al. (2019) a maior perda de transferência de calor para o ambiente foi dada para o diesel puro e no trabalho de Oliveira (2018), avaliando as misturas para cada faixa de carga aplicada, a maior perda se deu para a mistura com 25\% de biodiesel, onde foi a mistura máxima do combustível. Neste estudo observou-se que a mistura de B0 nas cargas de $500 \mathrm{~W}, 2000 \mathrm{~W}$ e $2500 \mathrm{~W}$ apresentou as maiores perdas de energia para o ambiente. Para a carga de $1000 \mathrm{~W}$ a maior perda de energia para a mistura de B20 e para $1500 \mathrm{~W}$ para a mistura de B10.

As menores perdas foram dadas para B100 para as cargas de $1000 \mathrm{~W}, 2000 \mathrm{~W}$ e $2500 \mathrm{~W}$, sendo de 6,04 kW, 8,39 kW e 10,36 kW, respectivamente. Na carga de $500 \mathrm{~W}$ a mistura que apresentou menor perda de energia para o ambiente foi B20, com 4,25 kW, e para a carga de $1500 \mathrm{~W}$ foi a mistura de B30 com $6,87 \mathrm{~kW}$. Este comportamento também foi observado no trabalho de Buyukkaya, et al. (2014).

\subsection{Análise exergética}

Foram calculados as exergias químicas para todas as misturas, para o diesel puro se chegou ao valor de 8822523,09 $\mathrm{kJ} / \mathrm{kmol}$ e para o biodiesel $11458472,6 \mathrm{~kJ} / \mathrm{kmol}$, o valor para o combustível diesel calculado foi bem próximo do disposto no trabalho de Jannatkhanh, et al. (2019), mas para o biodiesel o valor calculado foi 19,1\% maior que o disposto no estudo.

\subsubsection{Exergia do combustível}

A exergia do combustível é demonstrada pela Figura 5. Nota-se que a exergia do combustível cresce conforme se aumenta a carga aplicada. Para os trabalhos de Oliveira (2018), Uludamar e Sanli (2019) e Jannatkhanh, et al. (2019) as maiores exergias do combustível foram dadas para o diesel puro, notou-se o mesmo comportamento neste estudo, com exceção dos pontos para a mistura de B20 com carga de $1000 \mathrm{~W}$ e para a mistura de B10 com carga de $1500 \mathrm{~W}$ por apresentarem uma maior vazão de combustível. 
Figura 5 - Exergia do combustível para os combustíveis testados.

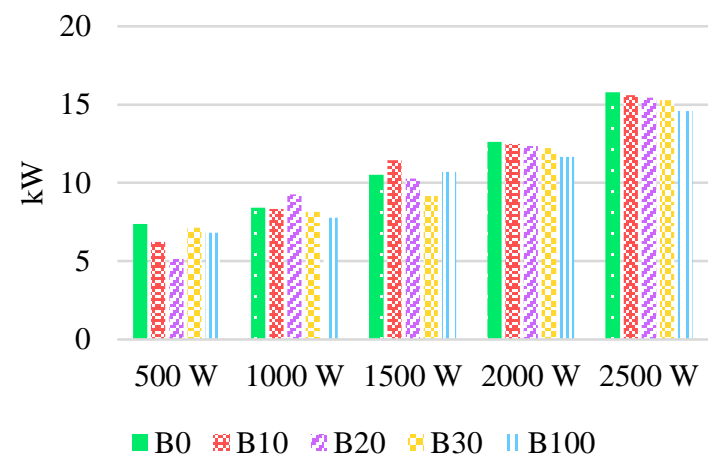

Fonte: Autores.

\subsubsection{Eficiência exergética}

À medida que se aumentou a carga do volume de controle a sua eficiência exergética crescia também, como pode ser observado a partir da Figura 6.

Ao se adicionar biodiesel ao óleo diesel ocorre um aumento da eficiência exergética (Jannatkhanh, et al., 2019), este comportamento foi observado para as cargas de $2000 \mathrm{~W}$ e de $2500 \mathrm{~W}$. Nas cargas de $1000 \mathrm{~W}, 2000 \mathrm{~W}$ e $2500 \mathrm{~W}$ a mistura de B100 foi a que apresentou a maior eficiência exergética, sendo de 12,86\% para carga de $1000 \mathrm{~W}$ e de 17,14\% para as cargas de $2000 \mathrm{~W}$ e $2500 \mathrm{~W}$. Na carga de $500 \mathrm{~W}$ a maior eficiência exergética foi de 9,72\% para a mistura de B20 e para carga de 1500 W foi de 16,36\% para a mistura de B30, estes pontos apresentaram valores de eficiência maiores devido sua vazão de combustível durante o ensaio ser menor que as outras em comparação ao mesmo ponto de carga.

Figura 6 - (a) Eficiência exergética dos combustíveis testados e (b) exergia dos gases de exaustão para os combustíveis testados.

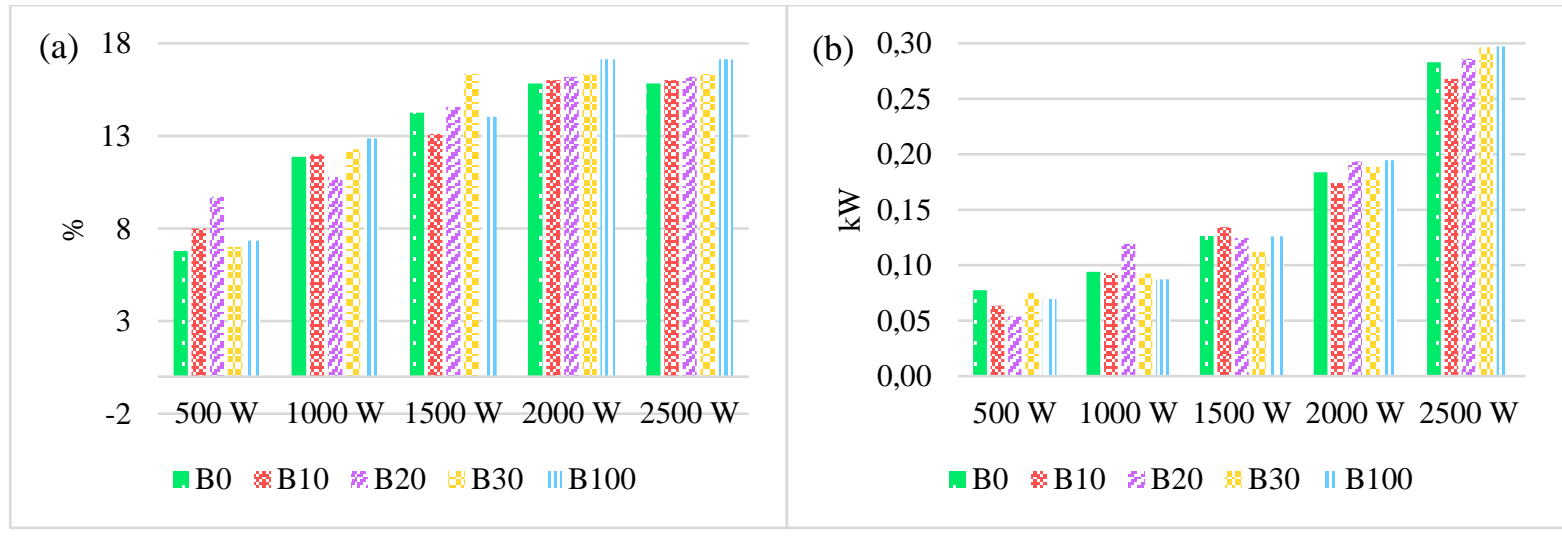

Fonte: Autores.

\subsubsection{Exergia dos gases de exaustão}

A Figura 5 apresenta os valores da exergia dos gases de exaustão $\left(\dot{n}_{c o m b} \bar{e}_{g e}\right)$. Observou-se que à medida que se aumentou a carga a exergia dos gases de exaustão aumentou também. No trabalho de Uludamar e Sanli (2019) e Karthickeyan (2019) a taxa de exergia dos gases de exaustão para o óleo diesel foi maior do que para os demais combustíveis. O mesmo comportamento só foi observado para a carga de $500 \mathrm{~W}$.

Para a carga de $500 \mathrm{~W}$ a mistura com maior exergia dos gases de exaustão foi a B0 e a menor foi para a mistura de B20. Na carga de 1000 W a maior energia dos gases de exaustão foi para a mistura de B20 e a menor foi para a mistura de B100. 
Avaliando para a carga de $1500 \mathrm{~W}$ a mistura de B10 demonstrou a maior exergia dos gases de exaustão e a mistura de B30 exibiu o menor valor.

Para as cargas de $2000 \mathrm{~W}$ e de $2500 \mathrm{~W}$ a mistura que apresentou a maior exergia dos gases de exaustão foi a B100. Além da mistura de B100, a mistura de B30 exibiu o mesmo valor de exergia para carga de $2500 \mathrm{~W}$. A mistura com a menor exergia foi a de B10 para a carga de $2000 \mathrm{~W}$ e $2500 \mathrm{~W}$.

\subsubsection{Exergia das perdas por transferência de calor}

A Figura 7 exibe a exergia das perdas por transferência de calor para cada combustível ensaiado. De acordo com Oliveira (2018) a exergia das perdas por transferência de calor é proporcional a quantidade de calor rejeitado pelo sistema e é similar as perdas por transferência de calor. Observou-se que com o aumento da carga a exergia das perdas por transferência de calor crescia.

No estudo de Buyukkaya, et al. (2014) o biodiesel apresentou a menor exergia por transferência de calor, o mesmo é observado para os pontos com carga de $1000 \mathrm{~W}, 2000 \mathrm{~W}$ e $2500 \mathrm{~W}$. Sendo os pontos que demonstraram comportamento diferente foi devido a sua vazão de combustível divergente das demais vazões.

Para a carga de $500 \mathrm{~W}$ a maior exergia das perdas por transferência de calor foi para a mistura de B0 e a menor foi para a mistura de B20. Na carga de $1000 \mathrm{~W}$ a mistura de B20 exibiu a maior exergia das perdas por transferência de calor e a mistura de B100 apresentou a menor exergia. A mistura que apresentou maior exergia das perdas por transferência de calor para a carga de $1500 \mathrm{~W}$ foi a B10 e a menor foi para B30.

Figura 7 - (a) Exergia das perdas por transferência de calor para os combustíveis testados e (b) exergia destruída dos combustíveis testados.

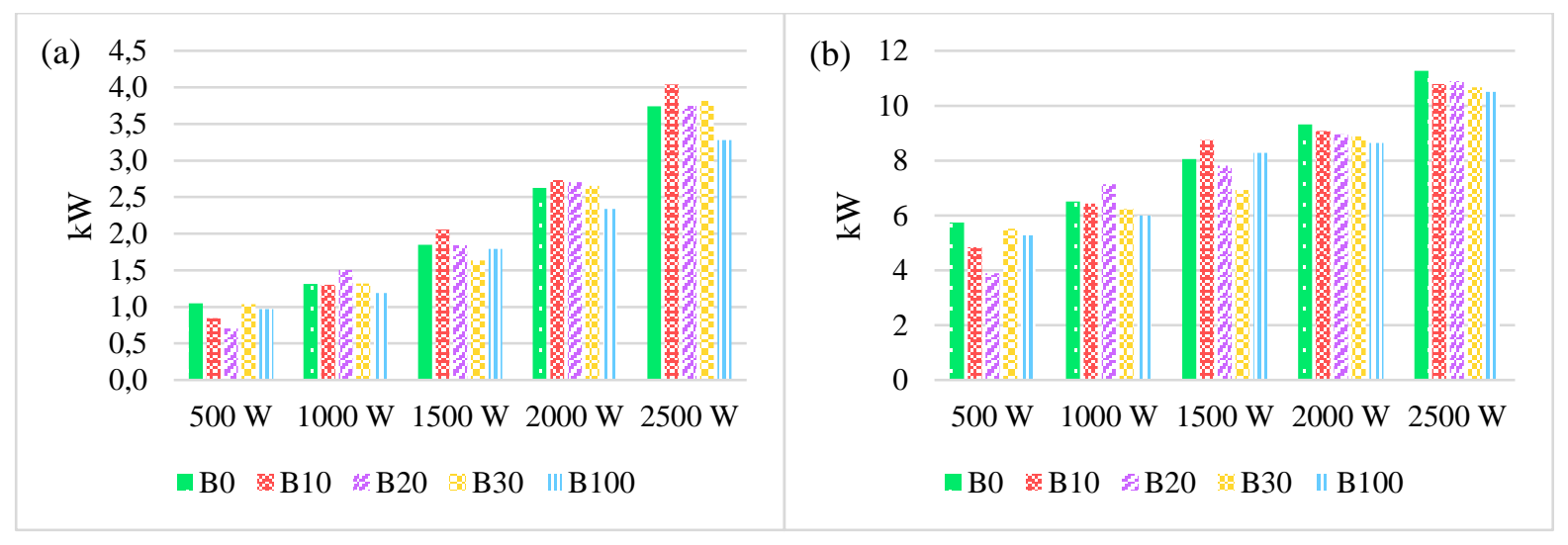

Fonte: Autores.

\subsubsection{Exergia destruída}

Verificou-se que a exergia destruída cresceu conforme se aumentava a carga, como pode ser visto na Figura 8. Para as cargas de $500 \mathrm{~W}, 2000 \mathrm{~W}$ e $2500 \mathrm{~W}$ a mistura que apresentou maior exergia destruída foi B0. Na carga de $1000 \mathrm{~W}$ a mistura que apresentou maior exergia destruída foi de B20 e para a carga de $1500 \mathrm{~W}$ foi a mistura de B10. O menor valor de exergia destruída para a carga de $1000 \mathrm{~W}, 2000 \mathrm{~W}$ e $2500 \mathrm{~W}$ foi para a mistura de B100. Na carga de $500 \mathrm{~W}$ a menor exergia destruída foi para a mistura de B20 e para $1500 \mathrm{~W}$ foi para B30.

Os estudos de Buyukkaya, et al. (2014), Oliveira (2018), Yamin, et al. (2018) e Jannatkhanh, et al. (2019), exibiram que a exergia destruída para o óleo diesel puro é maior do que para as misturas com biodiesel presente. Com exceção dos pontos 
que apresentaram uma vazão de combustível maior ou menor que as demais misturas para a faixa de carga analisada, todos os dados apresentaram comportamento semelhante ao exposto nos trabalhos acima citados.

\subsubsection{Distribuição de exergia}

A Figura 8 apresenta a distribuição de exergia para as diferentes misturas para cada carga aplicada respectiva. Nesta Figura estão dispostas a exergia gerada no volume de controle, a exergia dos gases de exaustão, a exergia perdida por transferência de calor e a exergia destruída para o volume de controle estabelecido em porcentagem.

Figura 8 - Distribuição de exergia para cada mistura e carga.

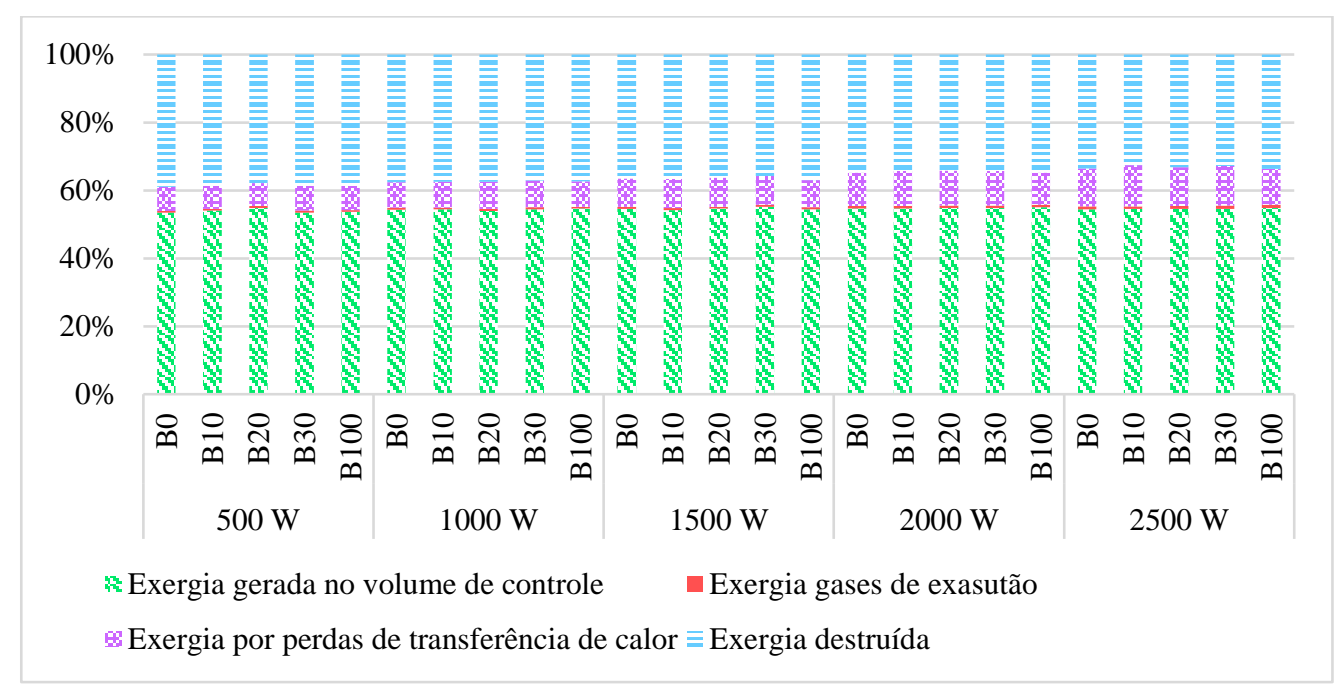

Fonte: Autores.

Observou-se porcentagens semelhantes para a exergia do combustível, da exergia dos gases de exaustão, da exergia por perdas de transferência de calor e da exergia destruída para as diferentes cargas e misturas. A exergia gerada no volume de controle correspondeu por mais da metade da exergia do sistema para todas as misturas e cargas. O ponto com a maior porcentagem de exergia do combustível foi para a mistura de B30 com carga de $1500 \mathrm{~W}$, corresponde a 55,17\%.

As exergias por perdas de transferência de calor e dos gases de exaustão não representam muito na distribuição de exergia, sendo a porcentagem máxima alcançada de 12,62\% para a mistura de B30 com carga de $2500 \mathrm{~W}$, a menor foi de 7,26\% para B10 com carga de $500 \mathrm{~W}$. A média da exergia destruída é de 36,51\%, a menor porcentagem de destruição de exergia foi de $32,52 \%$ para a mistura de B10 com carga de $2500 \mathrm{~W}$.

\section{Conclusão}

Por meio dos resultados obtidos, pode-se concluir que com o aumento da carga o consumo específico de combustível reduziu. O diesel puro exibiu menor consumo e maior energia do combustível do que as misturas com biodiesel e biodiesel puro. Os combustíveis com maior porcentagem de biodiesel apresentaram menores perdas de energia nos gases de exaustão e por transferência de calor. A maior eficiência térmica foi exibida para a mistura de B100 nas cargas de $2000 \mathrm{~W}$ e $2500 \mathrm{~W}$, sendo de $18,4 \%$.

A exergia do combustível é maior para o diesel puro do que para as misturas de diesel e biodiesel e o biodiesel puro. As maiores eficiências exergéticas foram para a carga de $2000 \mathrm{~W}$ e $2500 \mathrm{~W}$ para o biodiesel puro, correspondendo a 17,14\%. Ao aumentar a carga e a vazão de combustível a exergia do combustível também aumentou. As misturas que continham biodiesel 
exibiram menor destruição de exergia que a mistura apenas com diesel puro, sendo o biodiesel puro com a menor exergia destruída. A mistura de B10 apresentou a menor exergia dos gases de exaustão, mas para as demais misturas dos combustíveis o diesel puro exibiu menor exergia dos gases de exaustão que as demais misturas.

O biodiesel puro apresentou a menor exergia das perdas por transferência de calor, a mistura com 10\% de biodiesel alcançou os maiores valores de exergia. As demais misturas apresentaram valores semelhantes.

Os pontos com a mistura de B20 com carga de $500 \mathrm{~W}$ e de B30 com carga de $1500 \mathrm{~W}$ apresentaram vazões de combustível menores em comparação as outras misturas nas suas respectivas cargas avaliadas e os pontos de B20 com carga de $1000 \mathrm{~W}$ e de $\mathrm{B} 10$ com carga de $1500 \mathrm{~W}$ exibiram vazões maiores. Tais pontos manifestaram comportamento diferente das bibliografias utilizadas, o motivo desta divergência não pode ser identificado devido à falta de repetições dos ensaios.

Sugere-se para trabalhos futuros avaliar energeticamente e exergeticamente o motor gerador ciclo diesel com biodiesel proveniente de outras fontes, como, por exemplo, óleo de girassol, óleo de colza, óleo de cozinha usado, etc. Pode-se realizar o mesmo estudo alterando os parâmetros de operação do conjunto motor-gerador e também avaliando uma condição de combustão real, não a ideal como foi realizado neste estudo.

\section{Agradecimentos}

À todos os professores e colegas que de alguma forma auxiliaram no decorrer de todo trabalho e à Coordenação de Aperfeiçoamento de Pessoal de Nível Superior - Brasil (CAPES), pela concessão da bolsa para a realização desta pesquisa.

\section{Referências}

Agência Nacional de Petróleo, Gás Natural e Bicombustíveis (2020). Dados estatísticos. http://www.anp.gov.br/dados-estatisticos

Aghbashlo M., Tabatabaei M., Mohammadi P., Pourvosoughi N., Nikbakht A. M. \& Goli S. A. H. (2015). Improving exergetic and sustainability parameters of a DI diesel engine using polymer waste dissolved in biodiesel as a novel diesel additive. Energy Conversion and Management 105 : $328-337$. https://doi.org/10.1016/j.enconman.2015.07.075

Associação Brasileira de Normas Técnicas (2014). NBR 10441: Produtos de petróleo - Líquidos transparentes e opacos - Determinação da viscosidade cinemática e cálculo da viscosidade dinâmica.

Associação Brasileira de Normas Técnicas (2013). NBR 14065: Destilados de petróleo e óleos viscosos - Determinação da massa específica e da densidade relativa pelo densímetro digital.

Bergthorson J. M. \& Thomson, M. J (2015). A review of the combustion and emissions properties of advanced transportation biofuels and their impact on existing and future engines. Renewable and Sustainable Energy Reviews 42: 1393-1417. https://doi.org/10.1016/j.rser.2014.10.034

Brennan L. \& Owende P. (2010). Biofuels from microalgae-A review of technologies for production, processing, and extractions of biofuels and co-products. Renewable and Sustainable Energy Reviews 14 (2): 557-577. https://doi.org/10.1016/j.rser.2009.10.009

Buyukkaya E., Soyhan H. S. \& Gokalp B. (2014). Effects of rapeseed oil addition to a diesel fuel on thermodynamic efficiencies. International Journal of Exergy 14 (1): 101-124. https://doi.org/10.1504/IJEX.2014.059515

Canakci M. \& Hosoz M. (2006). Energy and exergy analyses of a diesel engine fuelled with various biodiesels. Energy Sources, Part B 1: 379-394. https://doi.org/10.1080/15567240500400796

Chuah L. F., Bokhari A., Yusup S., Klemes J. J., Abdullah B. \& Akbar M. M. (2016). Optimisation and Kinetic Studies of Acid Esterification of High Free Fatty Acid Rubber Seed Oil. Arabian Journal for Science and Engineering, 41 (7): 2515-2526. https://doi.org/10.1007/s13369-015-2014-1

Chuah L. F., Klemes J. J., Yusup S., Bokhari A. \& Akbar M. M. (2017). A review of cleaner intensification technologies in biodiesel production. Journal of Cleaner Production, 146: 181-193. https://doi.org/10.1016/j.jclepro.2016.05.017

Gashaw A. \& Teshita A. (2014). Production of biodiesel from waste cooking oil and factors affecting its formation: A review. International Journal of Renewable and Sustainable Energy, 3: 92-98.

Jannatkhah J., Najafi B. \& Ghaebi H. (2020). Energy and exergy analysis of combined ORC-ERC system for biodiesel-fed diesel engine waste heat recovery. Energy Conversion and Management, 209 (112658): 1-15. doi.org/10.1016/j.enconman.2020.112658

Kanoglu M., Isik S. K. \& Abusoglu A. (2005). Performance characteristics of a diesel engine power plant. Energy Conversion and Management, 46: 1692-1702. doi.org/10.1016/j.enconman.2004.10.005 
Research, Society and Development, v. 10, n. 16, e145101623471, 2021

(CC BY 4.0) | ISSN 2525-3409 | DOI: http://dx.doi.org/10.33448/rsd-v10i16.23471

Karthickeyan V. (2019). Effect of combustion chamber bowl geometry modification on engine performance, combustion and emission characteristics of biodiesel fuelled diesel engine with its energy and exergy analysis. Energy, 176: 830-852. doi.org/10.1016/j.energy.2019.04.012

Karthikeyan A. \& Jayaprabakar J. (2017). Energy and exergy analysis of compression ignition engine fuelled with rice bran biodiesel blends. International Journal of Ambient Energy, 1-7. doi.org/10.1080/01430750.2017.1399459

Knothe G., Razon L. F. (2017). Biodiesel fuels. Progress in Energy and Combustion Science, 58: 36-59. doi.org/10.1016/j.pecs.2016.08.001

Kotas T. J. (1985). The exergy method of thermal plant analysis. Elsevier.

López I., Quintana C. E., Ruiz J. J., Cruz-Peragón F. \& Dorado M. P. (2014). Effect of the use of olive-pomace oil biodiesel/diesel fuel blends in a compression ignition engine: Preliminary exergy analysis. Energy Conversion and Management, 85: 85:227-233. doi.org/10.1016/j.enconm+an.2014.05.084

Meira M., Santana P. M. B., Silva D. S., Catarino F. B. S., Borges L. F. J. \& Moreira L. B. (2016). Aditivos melhoradores da estabilidade oxidativa e corrosividade do biodiesel e da lubricidade da suas misturas com diesel. Revista Educação, Tecnologia e Cultura-ETC, 14 (14): 1-9. https://publicacoes.ifba.edu.br/index.php/etc/article/view/20

Moran M. S. \& Shapiro H. N. (2018). Fundamentals of Engineering Thermodynamics. Editora LTC.

Oliveira I. M. F. (2018). Análise experimental energética e exergética da combustão de um grupo gerador usando diesel e mistura biodiesel de soja. Trabalho de Conclusão de Curso, Universidade Federal da Grande Dourados.

Ouanji F., Khachani M., Boualag M., Kacimi M. \& Ziyad M. (2016). Large-scale biodiesel production from Moroccan used frying oil. International Journal of Hydrogen Energy, 41 (45): 21022-21029. doi.org/10.1016/j.ijhydene.2016.05.236

Patel R. L. \& Sankhavara C. D. (2017). Biodiesel production from Karanja oil and its use in diesel engine. A review. Renewable and Sustainable Energy Reviews, 71: 464-474. doi.org/10.1016/j.rser.2016.12.075

Szargut J., Morris D. \& Steward F. (1988) Exergy analysis of thermal chemical and metallurgical processes. United States, Berlin:Springer Verlag. 332p.

Turns S. R. (2013). Introdução à Combustão: Conceitos e Aplicações. AMGH Editora.

Sanli B. G. \& Uludamar E. (2019). Energy and exergy analysis of a diesel engine fuelled with diesel and biodiesel fuels at various engine speeds. Energy Sources Part A: Recovery, Utilization, and Environmental Effects, 42 (11): 1299-1313. doi.org/10.1080/15567036.2019.1635229

Yamin J. A., Sheet E. A. E. \& Hdaib I. (2018). Exergy analysis of biodiesel fueled direct injection CI engines. Energy Sources, Part A: Recovery, Utilization, and Environmental Effects, 40 (11): 1351-1358. doi.org/10.1080/15567036.2018.1476618 